\title{
STUDIES ON LEPTOSPIRA ICTEROHAEMORRHAGIAE. II. A CRITICAL STUDY OF THE EFFECT OF PENICILLIN ON LEPTOSPIRA ICTEROHAEMORRHAGIAE IN VITRO AND IN LEPTOSPIROSIS IN GUINEA PIGS
}

\author{
By SHIH LU CHANG \\ (From the Department of Comparative Pathology and Tropical Medicine, School of Medicine \\ and Public Health, Harvard University, Boston)
}

(Received for publication May 13, 1946)

Observations on the therapeutic effect of penicillin in both experimental and clinical leptospirosis have not been in full agreement. Heilman and Herrel (1) reported that of 32 guinea pigs which, 17 to 24 hours after the inoculation with $L$. icterohaemorrhagiae, received a total of 800 oxford units (hereafter abbreviated as o.u.) of penicillin daily for 7 days, 23 showed a complete suppression of leptospirosis, while 9 gave evidence of relapse 3 to 7 days after treatment. These 9 animals became normal after an additional 3 to 4 days of penicillin treatment.

On the other hand, Augustine, Weinman, and MacAllister (2) of this Department found that a course of penicillin, begun after the appearance of jaundice and amounting to 24,000 o.u. daily for about 3 days, failed to alter the fatal course of the infection in 5 guinea pigs. In another group of 4 guinea pigs in which the treatment, consisting of 30,000 o.u. daily for 2 days, was begun 38 hours after inoculation, none was patently ill, although 3 died between the 7th and 11th days after inoculation. At autopsy these 3 animals showed no severe lesions, but leptospirae were found in the liver and kidneys. These authors (Augustine et al.) thought that the death of the 5 animals in the first group might have been due to penicillin toxicity, and that penicillin might have some suppressive, but not curative, effect in leptospirosis.

Working with $L$. icterohaemorrhagiae in mice and L. canicola in hamsters, Larson and Griffiths (3) reported that the administration of penicillin to a total of 400 o.u. per mouse, and 1600 o.u. per hamster, produced a marked beneficial effect when the treatment was begun 48 to 52 hours after inoculation with leptospirae, less favorable results after 66 to 78 hours, and no apparent effect after 88 hours. These results suggest that the success of penicillin therapy in leptospirosis depends on its early administration.
Alston and Broom (4) found that the presence of 0.4 to 50 o.u. of penicillin in $3.5 \mathrm{ml}$. of culture medium stopped the multiplication of both $L$. icterohaemorrhagiae and $L$. canicola introduced in a rich inoculum. The addition of as much as 240 o.u. of penicillin per $10 \mathrm{ml}$. of a well grown culture of $L$. icterohaemorrhagiae greatly reduced the number of leptospirae after 12 days of incubation as compared with a control culture, although motile leptospirae were present even after 3 weeks of incubation. On this observation, they based their belief that penicillin has some lethal effect on leptospirae. Alston and Broom (4) also confirmed the results of Heilman and Herrel (1) that penicillin treatment, if started 18 hours after inoculation with leptospirae, exerted a favorable therapeutic action in guinea pigs. It is worth mentioning that these authors (4) observed no suppressive effect of penicillin on the development of serum antibodies in the treated animals.

Cross (5) infected 2 guinea pigs with $L$. icterohaemorrhagiae, and treated 1 animal 6 days after inoculation with 3000 o.u. of penicillin daily for 4 days. The treated animal showed no illness, whereas the untreated one died of leptospirosis 10 days after inoculation.

Information on the therapeutic effect of penicillin in human leptospirosis has been very scanty, and very few cases have been studied. Hart (6) reported a case of leptospirosis which recovered spontaneously, although the patient discharged leptospirae in the urine. Upon administration of 90,000 o.u. of penicillin daily for 3 days, the number of leptospirae in the urine diminished on the 2nd, and the organisms disappeared on the 3rd day of treatment. Cross (5) noted the recovery of a patient with leptospirosis after a combined treatment of $20 \mathrm{ml}$. of antiserum on the 9 th, 10th, and 11th days of the illness, and 120,000 o.u. of penicillin daily beginning on the 14th day, and 
continued until a total of 800,000 o.u. were given. Carragher (7) reported favorable response of another case of leptospirosis to penicillin therapy which was started on the 7th day of the illness, and consisted of 160,000 o.u. daily for 4 days. Bulmer (8) summarized the results of 39 cases of leptospirosis among British troops in Normandy, of which 16 were treated with penicillin at 240,000 o.u. daily to a total of about 1 million o.u. One among the treated cases died of uremia, as against 2 among the 23 untreated cases. The author (8) noted that the penicillin treatment produced marked symptomatic improvement in most of the cases that recovered, but its value in reducing the mortality rate is doubtful because of the fact that the treatment has generally been begun too late in the course of the disease to change the prognosis of fatal cases. Hutchison et al. (9) reported another group of 17 cases of leptospirosis among British troops in Italy, in which 6 received, from the 6th to the 10th day of illness, 120,000 o.u. of penicillin daily to a total of about 600,000 o.u., 3 received antiserum, and 8 remained untreated. One among the penicillin-treated, 1 among the serum-treated, and 2 among the untreated patients died. None of the other 5 who recovered in the penicillin-treated group showed evidence of benefiting from the penicillin.

In view of the present confused state of knowledge about the therapeutic value of penicillin in leptospirosis, the author attempted to study the nature of the activity of penicillin on $L$. icterohaemorrhagiae both in vitro and in guinea pigs, to find the minimum effective dose of penicillin in suppressing the disease process in guinea pigs, and to determine how far the disease may proceed before it is too late for the penicillin to modify its course.

\section{MATERIALS}

The strain of L. icterohaemorrhagiae used in this study was secured from the National Institute of Health, Bethesda, Maryland, through the Health Department of Boston, Massachusetts. It was maintained in culture in a fluid leptospira medium described previously (10). This strain, after several transfers, was of low virulence to experimental animals, and was used only in in vitro tests.

A virulent substrain of $L$. icterohaemorrhagiae was isolated in culture from a diseased guinea pig inoculated with the above mentioned strain of leptospira in a semisolid leptospira medium also described in the previous paper (10). The virulence of this substain was maintained in culture by a method described in the same paper.

As described previously (10), L. icterohaemorrhagiae grows prosperously in both media, and reaches the peak in about 2 weeks of incubation at $23^{\circ}$ to $26^{\circ} \mathrm{C}$., at which the leptospira density may be as high as 60 million per $\mathrm{ml}$. of culture. The virulent substrain, when inoculated in $0.5-\mathrm{ml}$. amounts intraperitoneally, in young guinea pigs (weighing 250 to 300 grams), almost always produced a fatal leptospirosis. Jaundice usually appeared on the 3rd or 4th day after inoculation.

The sodium salt of penicillin was used in this study, and was obtained commercially. A solution containing 5000 to 10,000 o.u. per ml. of solution was prepared in sterile distilled water shortly before use. The potency of each solution was tested against a culture of Staphylococcus aureaus. The solution was kept at $2^{\circ} \mathrm{C}$. when not in use, and was discarded after 48 hours' storage.

The procedures used in the different tests are described, and the results observed are presented and discussed, under the following separate headings.

\section{Activity of penicillin on L. icterohaemorrhagiae in water}

In order to understand better the effect of penicillin in leptospirosis, it is desirable to know precisely how penicillin acts on the leptospirae. Tests were, therefore, made first to determine the survival of leptospirae in water containing varying amounts of penicillin at various temperatures and lengths of storage.

Suspensions of leptospirae in water were prepared by centrifuging a 2 - to 3-weeks-old culture of $L$. icterohaemorrhagiae in the fluid medium at 4000 r.p.m. for 30 minutes, washing once, and resuspending the sediment in sterile tap water. The suspension thus prepared usually had about 20 million organisms per $\mathrm{ml}$. of water, about 90 per cent of which were motile. For the method of leptospira count, see the previous paper (10). Two ml. amounts of suspension were dispensed in a series of sterile small tubes, $10 \mathrm{~mm}$. in diameter. Dilutions containing 10, 100,1000, and 10,000 o.u. of penicillin in sterile distilled water were prepared from the stock solution. Two $\mathrm{ml}$. of each of these 4 dilutions were added to the tubes of leptospira suspension, and mixed. One tube of leptospira suspension without penicillin served as control. Of 3 sets of tubes thus prepared, 1 set was placed in a cold room at $10^{\circ} \mathrm{C}$, 1 set at room temperature $\left(23^{\circ}\right.$ C. \pm 1$)$, and 1 set in an incubator at $37^{\circ} \mathrm{C}$.

These tubes were examined by darkfield illumination for motile leptospirae every other day for a period of 2 weeks. In each examination, a 
total of about 100 organisms were counted, and the number of motile ones was expressed as percent of the total. The results thus obtained are presented in Table I.

Before discussing the data in Table $I$, it must be noted that in a separate study made on the survival of $L$. icterohaemorrhagiae in tap and Charles River waters, and in tap water containing 10 per cent sewage (11), it was found that although most of the leptospirae survived only the first few days of storage, a small number of them was capable of multiplying at very slow rate for a few weeks or more, depending on the temperature and the amount of nutritive substance in the water. While much of the nutrients of the culture was removed during the preparation of the suspension, a small remaining amount seemed to furnish sufficient food for the multiplication of a few leptospirae. Temperature seemed to affect the survival of leptospirae in several ways. In the presence of bacterial contamination, the higher temperatures favor the growth of bacteria which are detrimental to the survival of leptospirae. In the absence of bacterial contamination, the higher temperatures favor the rate of multiplication of leptospirae, but shorten the survival time of the individual leptospira which is no longer multiplying.

In the present study, the same phenomenon was noticed. As shown by Table $I$, in the controls a large per cent of the leptospirae became nonmotile in the first few days of storage. The decrease in the number of motile organisms is shown to be lowest at $10^{\circ} \mathrm{C}$, higher at $23^{\circ} \mathrm{C}$., and highest at $37^{\circ} \mathrm{C}$. However, the most important phenomenon brought out by the data in this table is that, with the presence of penicillin in amounts of from 5 to 5000 o.u., the percentages of motile leptospirae were not significantly different from that in the control up to the 12th day of storage at $10^{\circ} \mathrm{C}$., the 8 th day at $23^{\circ} \mathrm{C}$., and the 4th day at $37^{\circ} \mathrm{C}$. After these periods of storage, the controls showed slightly, but consistently, higher percentages of motile organisms than the penicillintreated. It must also be noted that while a few of the motile leptospirae in the controls showed evidence of multiplication (fission of long leptospirae was observed during microscopic examination) none of the penicillin-treated tubes showed such dividing forms. These results suggest that although the penicillin has no leptospiricidal effect even at high concentrations, it seems to prevent the reproduction of the leptospirae.

\section{Activity of penicillin on L. icterohaemorrhagiae in culture}

While the results of the above experiments clearly demonstrate that, in vitro, penicillin is not appreciably leptospiricidal, it is indicated that the drug may have an inhibitory effect on the reproduction of leptospirae. The following experiments were performed to gain information on this very question.

Each of a series of flasks of the fluid leptospira medium in $25 \mathrm{ml}$. amounts was seeded with $1 \mathrm{ml}$. of a well mixed, 2-weeks old culture of $L$. icterohaemorrhagiae. The initial leptospira density of the seeded medium in each flask was ascertained by the same counting method as described in the previous paper (10).

The seeded flasks were grouped into 3 sets, with 7 flasks in each set. Into each 6 flasks was added separately a 1-ml. amount of the penicillin solutions, containing 5,10 , $20,50,250$, and 1250 o.u. The final penicillin concentra-

TABLE I

Survival of $\mathrm{L}$. icterohaemorrhagiae in water containing varying amounts of penicillin

\begin{tabular}{|c|c|c|c|c|c|c|c|c|c|c|c|c|c|c|c|c|}
\hline \multirow{2}{*}{$\begin{array}{l}\text { No. of } \\
\text { days } \\
\text { stored }\end{array}$} & \multicolumn{6}{|c|}{ At $10^{\circ} \mathrm{C}$} & \multicolumn{5}{|c|}{ At $23^{\circ} \mathrm{C}$} & \multicolumn{5}{|c|}{ At $37^{\circ} \mathrm{C}$} \\
\hline & $\underset{\text { of peni. }}{\text { cillin }} \mid$ & 0 & 5 & 50 & 500 & 5000 & 0 & 5 & 50 & 500 & 5000 & 0 & 5 & 50 & 500 & 5000 \\
\hline $\begin{array}{c}\text { At start } \\
2 \\
4 \\
6 \\
8 \\
10 \\
12 \\
14\end{array}$ & $\begin{array}{l}96 \\
64 \\
55 \\
43 \\
28 \\
21 \\
17 \\
13\end{array}$ & & $\begin{array}{r}97 \\
72 \\
62 \\
40 \\
26 \\
19 \\
14 \\
6\end{array}$ & $\begin{array}{r}92 \\
60 \\
54 \\
35 \\
29 \\
22 \\
16 \\
4\end{array}$ & $\begin{array}{r}96 \\
65 \\
75 \\
36 \\
31 \\
19 \\
13 \\
5\end{array}$ & $\begin{array}{l}92 \\
61 \\
50 \\
39 \\
25 \\
17 \\
16 \\
5\end{array}$ & $\begin{array}{l}\text { perc } \\
94 \\
46 \\
37 \\
28 \\
15 \\
11 \\
10 \\
8\end{array}$ & $\begin{array}{c}a g e \text { of } \\
90 \\
43 \\
33 \\
25 \\
11 \\
5 \\
3 \\
2\end{array}$ & $\begin{array}{c}\text { ditle le } \\
97 \\
36 \\
28 \\
22 \\
14 \\
5 \\
4 \\
2\end{array}$ & $\begin{array}{c}\text { spira } \\
91 \\
41 \\
35 \\
26 \\
9 \\
8 \\
3 \\
1\end{array}$ & $\begin{array}{r}95 \\
39 \\
30 \\
25 \\
10 \\
6 \\
5 \\
2\end{array}$ & $\begin{array}{r}98 \\
20 \\
15 \\
5 \\
3 \\
1 \\
1 \\
0\end{array}$ & $\begin{array}{r}93 \\
24 \\
11 \\
2 \\
0 \\
0 \\
0 \\
0\end{array}$ & $\begin{array}{r}91 \\
19 \\
13 \\
1 \\
0 \\
0 \\
0 \\
0\end{array}$ & $\begin{array}{r}95 \\
22 \\
15 \\
2 \\
0 \\
0 \\
0 \\
0\end{array}$ & $\begin{array}{r}95 \\
21 \\
10 \\
1 \\
0 \\
0 \\
0 \\
0\end{array}$ \\
\hline
\end{tabular}


TABLE II

Leptospirostatic effect of penicillin in culture

\begin{tabular}{|c|c|c|c|c|c|c|c|c|}
\hline $\begin{array}{l}\text { No. of days } \\
\text { stored }\end{array}$ & $\begin{array}{c}\text { Peni- } \\
\text { cillin } \\
\text { o.u. per } \\
\text { m. }\end{array}$ & 0 & 0.2 & 0.4 & 0.8 & 2.0 & 10.0 & 50.0 \\
\hline $\begin{array}{c}A t 10^{\circ} \mathrm{C} \\
\text { Initial } \\
7 \\
14 \\
21 \\
28 \\
35\end{array}$ & $\begin{array}{l}8.1 \\
9.2 \\
1.3 \\
2.4 \\
2.9 \\
3.1\end{array}$ & $\begin{array}{l}10^{6} \\
10^{5} \\
10^{6} \\
10^{6} \\
10^{6} \\
10^{6}\end{array}$ & $\begin{array}{l}7.8 \times 10^{6} \\
8.6 \times 10^{6} \\
1.1 \times 10^{6} \\
1.8 \times 10^{6} \\
2.2 \times 10^{6} \\
2.5 \times 10^{6}\end{array}$ & $\begin{array}{l}8.5 \times 10^{5} \\
5.9 \times 10^{5} \\
1.8 \times 10^{6} \\
3.8 \times 10^{4} \\
1.2 \times 10^{4} \\
1.0 \times 10^{4}\end{array}$ & $\begin{array}{l}7.3 \times 10^{5} \\
5.4 \times 10^{5} \\
1.9 \times 10^{5} \\
3.7 \times 10^{4} \\
1.4 \times 10^{4} \\
1.0 \times 10^{4}\end{array}$ & $\begin{array}{l}\text { dewre } \\
7.5 \times 10^{5} \\
5.7 \times 10^{5} \\
1.1 \times 10^{6} \\
3.2 \times 10^{4} \\
1.8 \times 10^{4} \\
1.0 \times 10^{4}\end{array}$ & $\begin{array}{l}8.0 \times 10^{5} \\
6.1 \times 10^{5} \\
1.5 \times 10^{5} \\
3.5 \times 10^{4} \\
1.8 \times 10^{4} \\
1.0 \times 10^{4}\end{array}$ & $\begin{array}{l}8.3 \times 10^{5} \\
5.8 \times 10^{5} \\
1.1 \times 10^{5} \\
2.8 \times 10^{4} \\
1.1 \times 10^{4} \\
1.0 \times 10^{4}\end{array}$ \\
\hline $\begin{array}{c}\text { At } 23^{\circ} \mathrm{C} \\
\text { Initial } \\
4 \\
8 \\
12 \\
16 \\
18\end{array}$ & $\begin{array}{l}7.6 \\
2.0 \\
5.0 \\
1.5 \\
3.2 \\
3.4\end{array}$ & $\begin{array}{l}10^{5} \\
10^{6} \\
10^{6} \\
10^{7} \\
10^{7} \\
10^{7}\end{array}$ & $\begin{array}{l}8.0 \times 10^{6} \\
1.7 \times 10^{6} \\
4.5 \times 10^{6} \\
1.1 \times 10^{7} \\
2.4 \times 10^{7} \\
2.8 \times 10^{7}\end{array}$ & $\begin{array}{l}7.2 \times 10^{5} \\
4.6 \times 10^{5} \\
1.8 \times 10^{5} \\
5.3 \times 10^{4} \\
3.4 \times 10^{4} \\
4.3 \times 10^{4}\end{array}$ & $\begin{array}{l}7.9 \times 10^{5} \\
4.0 \times 10^{5} \\
1.5 \times 10^{5} \\
5.1 \times 10^{4} \\
2.5 \times 10^{4} \\
1.0 \times 10^{4}\end{array}$ & $\begin{array}{l}8.2 \times 10^{5} \\
4.4 \times 10^{5} \\
1.4 \times 10^{5} \\
4.5 \times 10^{4} \\
1.9 \times 10^{4} \\
1.0 \times 10^{4}\end{array}$ & $\begin{array}{l}7.5 \times 10^{5} \\
3.8 \times 10^{5} \\
2.0 \times 10^{5} \\
3.9 \times 10^{4} \\
2.1 \times 10^{4} \\
1.0 \times 10^{4}\end{array}$ & $\begin{array}{l}7.8 \times 10^{5} \\
4.3 \times 10^{5} \\
2.1 \times 10^{5} \\
4.1 \times 10^{4} \\
1.7 \times 10^{4} \\
1.0 \times 10^{4}\end{array}$ \\
\hline $\begin{array}{c}\text { At } 37^{\circ} \mathrm{C} \\
\text { Initial } \\
2 \\
4 \\
6 \\
8 \\
10 \\
12\end{array}$ & $\begin{array}{l}8.6 \\
2.7 \\
5.6 \\
1.1 \\
7.8 \\
4.8 \\
3.5\end{array}$ & & $\begin{array}{l}8.2 \times 10^{6} \\
2.2 \times 10^{6} \\
5.1 \times 10^{6} \\
8.8 \times 10^{6} \\
6.8 \times 10^{6} \\
5.6 \times 10^{6} \\
3.2 \times 10^{6}\end{array}$ & $\begin{array}{l}7.6 \times 10^{5} \\
2.5 \times 10^{5} \\
8.7 \times 10^{4} \\
4.5 \times 10^{4} \\
4.7 \times 10^{4} \\
5.0 \times 10^{4} \\
4.8 \times 10^{4}\end{array}$ & $\begin{array}{c}8.0 \times 10^{5} \\
2.8 \times 10^{5} \\
9.2 \times 10^{4} \\
2.3 \times 10^{4} \\
1.0 \times 10^{4} \\
1.0 \times 10^{4} \\
\pm\end{array}$ & $\begin{array}{c}7.9 \times 10^{5} \\
2.1 \times 10^{5} \\
8.5 \times 10^{4} \\
1.8 \times 10^{4} \\
1.0 \times 10^{4} \\
\pm \\
=\end{array}$ & $\begin{array}{c}7.5 \times 10^{5} \\
2.2 \times 10^{6} \\
9.0 \times 10^{4} \\
1.5 \times 10^{4} \\
1.0 \times 10^{4} \\
\pm \\
-\end{array}$ & $\begin{array}{c}7.8 \times 10^{5} \\
2.6 \times 10^{5} \\
8.4 \times 10^{4} \\
1.4 \times 10^{4} \\
1.0 \times 10^{4} \\
\pm \\
=\end{array}$ \\
\hline
\end{tabular}

tions were therefore $0.2,0.4,0.8,2.0,10.0$, and 50.0 o.u. per $\mathrm{ml}$. of the medium. The untreated flask served as a control. One set of flasks was held at $10^{\circ} \mathrm{C}$., 1 set at room temperature $\left(23^{\circ} \mathrm{C} . \pm 1\right)$, and 1 set at $37^{\circ} \mathrm{C}$. The leptospira density in each flask in each set was determined at scheduled time intervals by the same procedure previously described (10). The results thus obtained are summarized in Table II. Since many leptospirae were found dead in later periods of storage in the penicillintreated cultures, the figures presented in the table include only the motile organisms.

Before analyzing the data in Table II, it should be noted that $L$. icterohaemorrhagiae differed from ordinary vegetative bacteria in that it multiplied at such a slow rate in artificial media that the increase in number of organisms was measureable only at intervals of days (11). The higher incubation temperature increased the growth rate, but at $37^{\circ} \mathrm{C}$. the increase was observed only in the first few days, after which the growth dropped steadily. At $10^{\circ} \mathrm{C}$. the growth increase was barely measurable at weekly intervals. This slow growth rate made the study of the leptospirostatic effect of penicillin difficult, since significant differences in the number of leptospirae between the treated and control flasks was not noticeable until after several days of incubation at room or body tem- perature, and after several weeks at low temperatures. Deterioration of penicillin would have taken place during the period of observation.

In spite of the difficulty, the results indicate that penicillin has a definite leptospirostatic effect on L. icterohaemorrhagiae. Since penicillin is relatively stable at $10^{\circ} \mathrm{C}$. or below, the results obtained at $10^{\circ} \mathrm{C}$. may be interpreted without seriously considering the matter of deterioration of the penicillin. As shown in the first part of Table II, multiplication of leptospirae was stopped in the culture containing 0.4 o.u. of penicillin per ml., and the culture containing 0.1 o.u. showed an increase in the number of leptospirae not significantly different from that of the control. It is of importance to note again that further increase in the dosage of penicillin, even to as much as 50 o.u. per ml., produced no significant change in leptospirostatic effect. The data also indicate that at $10^{\circ} \mathrm{C}$. the majority of leptospirae survived less than 2 weeks, some survived less than 3 weeks, and a small number survived more than 4 weeks in the medium where penicillin exerted a leptospirastatic effect.

The results at $23^{\circ}$ and $37^{\circ} \mathrm{C}$. followed, in general, the same pattern as those of $10^{\circ} \mathrm{C}$., except 
that the differences in the number of leptospirae were much greater between cultures with and without the leptospirostatic effect of penicillin. These accentuated differences at higher temperatures are attributed to the fact that the leptospirae multipled at greater speeds, and that, when they failed to multiply as under leptospirostatic effect, they survived a shorter time at these temperatures. It is also noteworthy that the culture containing 0.4 o.u. of penicillin per ml. showed a slight increase in the number of leptospirae after a steady decrease in 12 days of incubation at $23^{\circ} \mathrm{C}$. A similar result was observed in the culture containing the same amount of penicillin after 4 days of incubation at $37^{\circ} \mathrm{C}$. This phenomenon is explained on the basis that the amount of penicillin present in these cultures might have deteriorated to a level at which it no longer inhibited reproduction.

A determination of the residual penicillin by the method described by Fleming (12) was made
TABLE III

Deterioration of Penicillin in Cultures of $L$. icterohaemorrhagiae

\begin{tabular}{c|c|c|c|c|c|c|c}
\hline \hline $\begin{array}{c}\text { Incu- } \\
\text { bation } \\
\text { temp. }\end{array}$ & $\begin{array}{c}\text { Days } \\
\text { of in- } \\
\text { cuba- } \\
\text { tion }\end{array}$ & \multicolumn{5}{|c}{ Amount of penicillin in o.u. per ml. of Culture } \\
\cline { 3 - 8 } & Initial & Residual & Initial & Residual & Initial & Residual \\
\hline $23^{\circ} \mathrm{C}$ & 16 & 0.4 & 0.1 & 0.8 & 0.4 & 2.0 & 0.5 \\
$37^{\circ} \mathrm{C}$ & 6 & 0.4 & $<0.1$ & 0.8 & 0.2 & 2.0 & $<0.5$ \\
\hline
\end{tabular}

on the 16 th day of incubation at $23^{\circ} \mathrm{C}$., and on the 6th day at $37^{\circ} \mathrm{C}$. on the cultures containing initial amounts of $0.4,0.8$, and 2.0 o.u. of penicillin per $\mathrm{ml}$. The results, as presented in Table III, showed that roughly 50 to 75 per cent of the penicillin had deteriorated.

Summing up these results, one may conclude that penicillin is definitely leptospirostatic in culture, and that in order to obtain a leptospirostatic effect, a minimum dosage of 0.4 o.u. of penicillin per ml. of medium is necessary. No advantage is gained by increasing the amount of penicillin, pro-

TABLE IV

Effect of penicillin on L. icterohaemorrhagiae in guinea pigs

\begin{tabular}{|c|c|c|c|c|c|c|c|c|c|c|c|c|}
\hline \multirow{3}{*}{$\begin{array}{l}\text { Group } \\
\text { no. of } \\
\text { guinea } \\
\text { pig }\end{array}$} & \multirow{3}{*}{$\begin{array}{l}\text { Peni- } \\
\text { cillin }\end{array}$} & \multicolumn{10}{|c|}{ Cultural results and serum penicillin levels at stated days after inoculation } & \multirow{3}{*}{ Remarks* } \\
\hline & & \multicolumn{2}{|c|}{1} & \multicolumn{2}{|c|}{3} & \multicolumn{2}{|c|}{5} & \multicolumn{2}{|c|}{7} & \multicolumn{2}{|c|}{9} & \\
\hline & & NPCi & SPL $^{2}$ & NPC & SPL & NPC & SPL & NPC & SPL & NPC & SPL & \\
\hline I & $\begin{array}{r}\text { o.u. per } \\
\text { day } \\
0\end{array}$ & $6 / 6$ & 0 & $6 / 6$ & 0 & $4 / 4$ & - & $2 / 2$ & - & 一 & - & $\begin{array}{l}1 \text { died on the } 5 \text { th, } 1 \text { on the } 7 \text { th, } \\
\text { and } 1 \text { on the } 8 \text { th day }\end{array}$ \\
\hline II & 100 & $6 / 6$ & $<0.1$ & $6 / 6$ & $<0.1$ & $6 / 6$ & $<0.1$ & $4 / 4$ & - & $2 / 2$ & - & $\begin{array}{l}1 \text { died on the } 7 \text { th, } 1 \text { on the } 8 \text { th, } \\
\text { and } 1 \text { on the } 9 \text { th day }\end{array}$ \\
\hline III & 200 & $6 / 6$ & 0.1 & $6 / 6$ & $>0.1$ & $6 / 6$ & 0.1 & $5 / 6$ & - & $3 / 4$ & - & $\begin{array}{l}1 \text { died on the } 9 \text { th, and } 2 \text { died on } \\
\text { the } 10 \text { th day }\end{array}$ \\
\hline IV & 400 & $6 / 6$ & $>0.1$ & $6 / 6$ & $>0.1$ & $5 / 6$ & $<0.2$ & $5 / 6$ & - & $3 / 4$ & - & $\begin{array}{l}1 \text { died on the } 9 \text { th, } 1 \text { died on the } \\
11 \text { th day, } 1 \text { sick on the } 12 \text { th day } \\
\text { and recovered }\end{array}$ \\
\hline V & 600 & $6 / 6$ & $>0.2$ & $4 / 6$ & $>0.2$ & $2 / 6$ & $>0.2$ & $0 / 6$ & - & $1 / 6$ & - & $\begin{array}{l}1 \text { sick on the } 10 \text { th day and died, } \\
1 \text { sick on the } 13 \text { th day and re- } \\
\text { covered, } 1 \text { normal }\end{array}$ \\
\hline VI & 800 & $6 / 6$ & 0.4 & $2 / 6$ & $>0.4$ & $0 / 6$ & 0.4 & $0 / 6$ & - & $0 / 6$ & - & $\begin{array}{l}1 \text { sick on } 13 \text { th day and recovered, } \\
2 \text { normal }\end{array}$ \\
\hline VII & 1,000 & $6 / 6$ & $>0.4$ & $3 / 6$ & $>0.4$ & $0 / 6$ & $>0.4$ & $0 / 6$ & - & $0 / 6$ & - & $\begin{array}{l}1 \text { sick on } 14 \text { th day and recovered, } \\
2 \text { normal }\end{array}$ \\
\hline VIII & $5,000^{4}$ & $6 / 6$ & 0.6 & $2 / 6$ & 0.2 & $0 / 6$ & $<0.1$ & $1 / 6$ & - & $3 / 6$ & - & $\begin{array}{l}1 \text { sick on 10th day, } 2 \text { sick on } 11 \text { th } \\
\text { day, } 2 \text { died, } 1 \text { recovered }\end{array}$ \\
\hline
\end{tabular}

$1 \mathrm{NPC}=$ Number of cultures positive for leptospira.

2 SPL = Serum penicillin level in o.u. per ml. of serum.

8 All animals that died showed jaundice before death, and typical haemorrhages and leptospirae in liver at autopsy.

S Single dose given together with the infective inoculum. 
vided the 0.4 o.u. per $\mathrm{ml}$. level is maintained during the surviving period.

Effect of Penicillin on L. icterohaemorrhagiae in Guinea Pigs

Having observed the leptospirostatic effect of penicillin in culture, a study was then made of the effect of penicillin on L. icterohaemorrhagiae in guinea pigs.

Tests were made in 24 animals weighing 250 to 300 grams. Since it is essential in these tests to have a suffcient number of leptospirae in the blood of inoculated animals to give positive cultures even with a small inoculum, each animal received intraperitoneally $5 \mathrm{ml}$. of a 2 -weeks old culture of the virulent substrain of $L$. icterohaemorrhagiae, containing about 40 million organisms per $\mathrm{ml}$. These animals were divided into 8 groups of 3 individuals. Each animal of 6 groups received, 12 hours after inoculation, penicillin at dosages of $50,100,200,300,400$, and 500 o.u. twice daily for a period of 7 days respectively. One group of animals received a single dose of 5000 o.u. of penicillin per animal shortly after the inoculation. The last group received no penicillin, serving as control.

Blood samples of $0.2 \mathrm{ml}$. amounts were taken by cardiac puncture from all animals $1,3,5,7$, and 9 days after inoculation. One of the 3 samples from each group was used for determining the serum level of penicillin, and the other 2 were inoculated in $0.1 \mathrm{ml}$. amounts into the 6 flasks of semisolid leptospira medium, and incubated at room temperature. The dilution of the blood in the medium was so high $(0.1: 25)$ that the amount of penicillin carried into the medium was far below the level necessary to exert leptospirostatic effect. The results thus obtained are summarized in Table IV.
As shown in Table IV, with a daily dosage of 600 to 800 o.u. of penicillin per animal, no leptospirae were recovered from the $0.3 \mathrm{ml}$. of blood taken 5 days after inoculation, when the serum penicillin level was between over 0.2 to 0.4 o.u. per $\mathrm{ml}$. The results obtained with a daily dose of 1000 o.u. of penicillin were essentially the same as those with 800 o.u., confirming the former observation on cultures that no advantage is gained by increasing the dosage of penicillin when a leptospirostatic level has been reached. However, the fact that 2 of the 3 animals in Group V showed relapse in 4 to 6 days, and that 1 individual in each of Groups VI and VII relapsed 6 to 7 days after the last dose of penicillin, suggests that some leptospirae may have penetrated into the liver parenchyma in the early days after inoculation, where the amount of penicillin might have failed to reach a leptospirostatic level. When the serum penicillin dropped to sub-leptospirostatic level after the treatment was stopped, multiplication of the leptospirae was resumed and disease produced. It is of interest to note that most of the animals suffering from relapse recovered spontaneously, suggesting that some immunity had already been acquired by these animals which was able to stem the natural course of the disease.

To confirm these assumptions, 6 guinea pigs (weighing 250 to 300 grams) were inoculated with the virulent substrain of $L$. icterohaemorrhagiae in a similar way as before. Four animals received, beginning 12 hours after inoculation, 400 o.u. of penicillin twice daily, and 2 re-

TABLE V

Effect of penicillin on L. icterohaemorrhagiae in blood and liver of, and on antibody response in, guinea pigs

\begin{tabular}{|c|c|c|c|c|c|c|c|c|c|c|c|c|c|c|c|}
\hline \multirow{3}{*}{$\begin{array}{c}\text { Guinee } \\
\text { pis } \\
\text { no. }\end{array}$} & \multirow{3}{*}{ Peni- } & \multicolumn{5}{|c|}{ No. of pooitive blood cultures } & \multicolumn{3}{|c|}{ Serum penicillin level } & \multirow{2}{*}{\multicolumn{2}{|c|}{$\begin{array}{l}\text { Leptospira in } \\
\text { liver at } \\
\text { autopey }\end{array}$}} & \multirow{2}{*}{\multicolumn{4}{|c|}{$\frac{\text { Agglutination titer of sera }}{\text { days after inoculation }}$}} \\
\hline & & \multicolumn{5}{|c|}{ days after inoculation } & \multicolumn{3}{|c|}{ days afler inoculations } & & & & & & \\
\hline & & 1 & 3 & 5 & 7 & 9 & 3 & $\mathbf{s}$ & 7 & D.E.* & Culture & 7 & 11 & 15 & 19 \\
\hline $\begin{array}{l}1 \\
2 \\
3 \\
4\end{array}$ & $\begin{array}{r}\text { 0.4. per } \\
\text { doy } \\
800 \\
800 \\
3,000 \\
3,000\end{array}$ & $\begin{array}{l}2 / 2 \\
2 / 2 \\
2 / 2 \\
2 / 2\end{array}$ & $\begin{array}{l}1 / 2 \\
1 / 2 \\
1 / 2 \\
1 / 2\end{array}$ & $\begin{array}{l}0 / 2 \\
1 / 2 \\
0 / 2 \\
0 / 2\end{array}$ & $\begin{array}{l}0 / 2 \\
0 / 2 \\
0 / 2 \\
0 / 2\end{array}$ & $\begin{array}{l}0 / 2 \\
0 / 2\end{array}$ & $\begin{array}{l}0.2 \\
0.4 \\
0.8 \\
0.6\end{array}$ & $\begin{array}{l}\text { per } \\
0.4 \\
0.2 \\
0.6 \\
0.6\end{array}$ & $\begin{array}{l}0.4 \\
0.4 \\
1.0 \\
0.8\end{array}$ & $\begin{array}{l}-t \\
- \\
-\end{array}$ & $\bar{z}$ & & & & \\
\hline 5 & 800 & $2 / 2$ & $1 / 2$ & $0 / 2$ & $0 / 2$ & $0 / 2$ & & & & & & $\frac{1}{40}$ & $\frac{1}{160}$ & $\frac{1}{320}$ & $\frac{1}{640}$ \\
\hline 6 & 800 & $2 / 2$ & $1 / 2$ & $0 / 2$ & $0 / 2$ & $0 / 2$ & & & & & & $\frac{1}{20}$ & $\frac{1}{80}$ & $\frac{1}{160}$ & $\frac{1}{320}$ \\
\hline
\end{tabular}

* D.E. - Direct examination in darkfield.

t Although the livers from the first 4 animals were positive for living leptospirae, the numbers found in direct examination were very small, much smaller than found in ordinary untreated infected animals. 
ceived 1500 o.u. twice daily. Penicillin administration was continued for 7 days. Blood was taken and cultured for leptospira as before. The serum penicillin was again determined in 2 of the 4 animals that received 800 o.u. daily, and in the 2 that received 3000 o.u. on the $3 \mathrm{rd}, 5$ th, and 7 th day after inoculation. One in each 2 of these animals was sacrificed on the 9th day, and the other 2 on the 11th day after inoculation. From each animal a piece of liver was removed and emulsified in sterile normal saline and examined for living leptospirae directly, by darkfield, and by cultures. From the other 2 animals that received 800 o.u. daily of penicillin, blood samples were taken on the 7 th, 11 th, 15 th, and 19th day after inoculation. The sera were tested for agglutinins with a suspenion of formolized L. icterohacmorrhagiae. The results thus obtained are presented in Table V.

From Table V it is shown that, as noted before, leptospirae in the blood of guinea pigs were no longer recovered in culture after a period of about 5 days under the leptospirostatic effect of penicillin. However, even with a daily dose of 3000 o.u. of penicillin, resulting in a serum penicillin level of over 0.6 to 1.0 o.u. per ml., living leptospirae were still found in the liver 9 to 11 days after inoculation, or 6 to 8 days after the blood yielded negative cultures. It is too complicated to determine the tissue penicillin level in the liver; but it would seem either that penicillin failed to reach a leptospirostatic level in the liver in spite of the high serum penicillin level, or that the liver parenchyma has some penicillin-neutralizing power, thus offering a haven for small numbers of leptospirae. In this connection, it is interesting to note that Augustine et al. (2) found living leptospirae in the liver of the 3 guinea pigs that had received 30,000 o.u. of penicillin 38 hours after inoculation daily for 2 days, and had died of apparent penicillin toxicity on the 7 th, 8 th, and 11 th days.

The findings on the agglutination titre of the sera from guinea pigs Nos. 5 and 6 are in agreement with that of Alston and Broom (4) that the penicillin adminstration did not prevent the production of agglutinating antibodies, although the titres were not as high as would be observed in ordinary infection. This moderate antibody production is thought to be a response to the large number of leptospirae which failed to multiply, and died in the first few days after inoculation, and is held responsible for the spontaneous recovery of the animals that underwent relapse.

\section{Effect of penicillin in leptospirosis in guinea pigs}

Having observed the leptospirostatic effect of penicillin on L. icterohaemorrhagiae in guinea pigs, a study was finally attempted of the therapeutic effect of penicillin in leptospirosis in guinea pigs, particularly of the effect at various stages of the disease process.

Twenty young guinea pigs (weighing 250 to 300 grams) were inoculated in the same way as in the 2 previous test's with the virulent culture of $L$. icterohaemorrhagiae. These animals were divided into $\mathbf{5}$ groups. Four groups received 500 o.u. of penicillin twice daily for a period of 7 days (unless death occurred during treatment) starting 3, 4, 5, and 6 days after the inoculation. The last group was not treated, and served as a control. The results recorded in this experiment are shown in Table VI.

The results presented in Table VI, together with those in Tables IV and V, show clearly that peni-

TABLE VI

Effect of penicillin treatment on leptospirosis in guinea pigs

\begin{tabular}{|c|c|c|c|c|}
\hline $\begin{array}{l}\text { Group } \\
\text { no. of } \\
\text { guinea } \\
\text { pig }\end{array}$ & Penicillin & $\begin{array}{l}\text { Time lapse } \\
\text { between } \\
\text { inoculation } \\
\text { and } \\
\text { treatment }\end{array}$ & $\begin{array}{l}\text { Condition of animals at the time } \\
\text { when treatment began }\end{array}$ & Results of penicillin treatment* \\
\hline & $\begin{array}{l}\text { o.u. per } \\
\text { day }\end{array}$ & days & & \\
\hline 1 & 1,000 & 3 & $\begin{array}{l}\text { All showed loss of appetite, } 3 \text { with } \\
\text { roughness of fur, } 2 \text { with slightly } \\
\text { yellow tinged ears }\end{array}$ & $\begin{array}{l}\text { The } 2 \text { showing slight jaundice died on the } 6 \text { th } \\
\text { and } 7 \text { th days. The other } 2 \text { recovered with- } \\
\text { out showing apparent jaundice }\end{array}$ \\
\hline 2 & 1,000 & 4 & All were sick with moderate jaundice & All died, 1 on the 6 th, 3 on the 7 th day after \\
\hline 3 & 1,000 & 5 & All very sick, 3 with intense jaundice & All died, 2 on the 6 th, 2 on the 7 th day after \\
\hline 4 & 1,000 & 6 & One died, 2 very sick as in Group 3 & All 3 died on the 7 th day after inoculation \\
\hline
\end{tabular}

* All dead animals were autopsied and showed typical haemorrhages and large numbers of living leptospirae in their livers.

All 4 animals in control group died of the disease 4 to 5 days after inoculation. 
cillin, through its leptospirostatic effect, suppresses the development of leptospirosis, when it is administered during the incubation period and in amount adequate to maintain a serum level of about 0.4 o.u. per $\mathrm{ml}$. for a period of 7 days. The therapeutic effect may still be observed if penicillin is given before jaundice occurs. After the appearance of jaundice, the effect of penicillin is insignificant. This observation is, in general, in agreement with that of Larson and Griffitts (3), and confirms the statement made by Augustine $e t$ al. (2) that penicillin may have suppressive effect in leptospirosis if it is given before symptoms occur.

It must be noted that the 2 animals in Group 1 that recovered when penicillin was given shortly after the animals became sick, showed definite improvement on the 2nd day of treatment, and returned to normal on the 3rd day. Those animals that died in spite of the treatment, showed no apparent improvement in symptoms. This observation seems to support the statement made by Bulmer (8) that penicillin treatment in human leptospirosis resulted in symptomatic improvement in cases that were to recover, but was generally introduced too late to change the course of fatal cases. It would seem that in infections in which the liver is involved, death is a result of the liver damage which may not be checked or improved, even when the causative agent has been brought under control.

\section{SUMMARY AND CONCLUSIONS}

A study has been made of the effect of penicillin on L. icterohaemorrhagiae in water, in culture, and in guinea pigs, and also on the therapeutic effect in leptospirosis in guinea pigs. In this study, the following points have been observed.

1. Penicillin in an amount of about 0.4 o.u. per $\mathrm{ml}$. or more, in vitro, exerted a leptospirostatic effect, but showed no leptospirocidal effect even at concentrations as high as 5000 o.u. per ml. Being unable to multiply, the leptospirae survived a limited number of days only, more days at low temperatures, and fewer days at higher temperatures.

2. The leptospirostatic effect was also observed in guinea pigs as evidenced by the disappearance of leptospirae from the blood 3 to 5 days after inoculation, when a daily dosage of about 800 o.u. and a serum level of over 0.2 o.u. per $\mathrm{ml}$. were maintained. This, however, did not clear the liver of leptospirae. No advantage was obtained by increasing the dose to 3000 o.u. daily.

3. Some guinea pigs in which the development of leptospirosis was suppressed by early administration of penicillin relapsed several days after the last dose of penicillin, but recovered spontaneously in most cases. The recovery was attributed to the partial immunity developed in response to the large number of organisms inoculated. Agglutination tests made showed that fair amounts of antibodies were produced, in spite of the fact that penicillin suppressed the development of leptospirosis.

4. Penicillin seemed to have some therapeutic effect in infected guinea pigs if the treatment was introduced before the appearance of jaundice. After the appearance of jaundice, none of the animals tested appeared to benefit by the treatment.

From these observations, it is concluded that (1) penicillin has no leptospiricidal effect, but (2) has a leptospirostatic effect both in vitro and in vivo when a concentration of about 0.4 o.u. of penicillin per ml. is maintained, and (3) that the therapeutic effect of penicillin in leptospirosis in guinea pigs depends on its administration before the appearance of jaundice or, in other words, before the liver is seriously damaged. Judging from the data on the dosage and serum level of penicillin necessary to produce a leptospirostatic effect in guinea pigs, it is estimated that a daily dose of 250,000 to 300,000 o.u. should be administered to human cases to show a leptospirostatic effect. In view of the fact that leptospirosis in young guinea pigs is a much more serious disease than that in human beings, these results should not discourage the use of penicillin in human cases, even though the treatment is usually started after symptoms have developed.

The author is grateful to Dr. Donald L. Augustine for his kindness in reading the manuscript and making suggestions.

\section{BIBLIOGRAPHY}

1. Heilman, F. R., and Herrel, W. E., Penicillin in the treatment of experimental leptospirosis icterohaemorrhagica. Proc. Staff Meet., Mayo Clinic, 1944, 19, 89.

2. Augustine, D. L., Weinman, D., and MacAllister, J., Penicillin sodium therapy in experimental Weil's disease. New Eng. J. Med., 1944, 231, 358. 
3. Larson, C. L., and Griffitts, J. J., A comparison of the effect of penicillin and immune serum in the treatment of experimental leptospirosis in young white mice and in hamsters. Pub. Health Rept., 1945, $60,317$.

4. Alston, J. M., and Broom, J. C., The action of penicillin on leptospira, and on leptospiral infections in guinea pigs. Brit. M. J., 1944, 2, 718.

5. Cross, R. M., Penicillin in Weil's disease. Lancet, $1945,1,211$.

6. Hart, V. L., A case of Weil's disease treated with penicillin. Brit. M. J., 1944, 2, 720.

7. Carragher, A. E., A case of Weil's disease treated with penicillin. Brit. M. J., 1945, 1, 119.

8. Bulmer, E., Weil's disease in Normandy: its treatment with penicillin. Brit. M. J., 1945, 1, 113.

9. Hutchison, J. H., Pippard, J. S., Gleeson-White, M. H., and Sheehan, H. L., Outbreak of Weil's disease in the British army in Italy. Ibid., 1946, Part I, p. 81.

10. Chang, S. L., Studies on Leptospira icterohemorrhagiae: I. A fluid, and a semisolid medium for growing $L$. icterohemorrhagiae, $L$. canicola, and $L$. bifluxor, and a method for maintaining the virulence of $L$. icterohemorrhagiae in culture. J. Inf. Dis., In press.

11. Chang, S. L., Unpublished data obtained in a study on the survival of $L$. icterohemorrhagiae in water and on destruction of the same by halogen compounds and detergents. Work done under a contract between the Office of Scientific Research and Development and Harvard University.

12. Fleming, A., Streptococcal meningitis treated with penicillin: measurement of bacteriostatic power of blood and cerebrospinal fluid. Lancet, 1943, 2, 434. 